Jurnal Teknik Komputer AMIK BSI

Volume 7, No.2, Juli 2021

P-ISSN 2442-2436, E-ISSN: 2550-0120

Akreditasi Ristekdikti, No: 36/E/KPT/2019 (Sinta 4)

DOI: $10.31294 /$ jtk.v4i2

\title{
Prediksi Status Pinjaman Bank dengan Deep Learning Neural Network (DNN)
}

\author{
Sukri Syafudin ${ }^{1}$, Ranu Agastya Nugraha ${ }^{2}$, Kartika Handayani $^{3}$, Windu Gata ${ }^{4}$, Safitri Linawati ${ }^{5}$ \\ 1,2,3,4,5 Universitas Nusa Mandiri \\ 114002436@nusamandiri.ac.id \\ 214002433@nusamandiri.ac.id \\ 314002416@nusamandiri.ac.id \\ ${ }^{4}$ windu@nusamandiri.ac.id \\ $5^{5}$ safitri.swt@ nusamandiri.ac.id
}

\begin{tabular}{ccc}
\hline Diterima & Direvisi & Disetujui \\
$07-04-2021$ & $08-06-2021$ & $15-06-2021$ \\
\hline
\end{tabular}

\begin{abstract}
Abstrak - Penilaian risiko pada penentuan status pinjaman merupakan proses yang penting dalam usaha simpan pinjam. Prediksi dalam mengklasifikasikan apakah nasabah akan melunasi atau tidak akan menentukan pengambilan keputusan dan tindaklanjutnya yang berdampak pada kinerja entitas dalam menjalankan usahanya. Berbagai teknik dalam prediksi pinjaman bank dengan machine learning diterapkan dengan hasil yang meningkat dalam akurasi dan performance. Metode Deep Learning Neural Network (DNN) merupakan salah satu metode machine learning yang sekarang ini memiliki peran penting di era big data dimana data yang besar, dengan kemampuan mesin yang mumpuni dan kompleksitas pada suatu fitur mampu ditangani oleh DNN. Penelitian ini memvariasikan beberapa arsitektur dan parameter dalam pembangunan model DNN dengan score yang terbaik. Pengujian terhadap dataset bank loan status dengan metode DNN menghasilkan akurasi 82.27\% tidak lebih baik dari metode SVM dengan hasil akurasi $84 \%$. Namun metode DNN masih lebih baik dibandingkan dengan metode lainnya. Karena penggunaan variasi arsitektur dan parameter DNN tidak berpengaruh signifikan dalam menghasilkan score terbaik. Data yang diproses benar-benar diperlukan pemrosesan lebih lanjut sebelum dilakukan pemodelan.
\end{abstract}

Kata Kunci: prediksi pinjaman bank, deep learning, dnn

Abstract - Risk assessment in determining loan status is an important process in a savings and loan business. The prediction in classifying whether the customer will pay off or not will determine the decision-making and follow-up that will impact the performance of the entity in conducting its business. Various techniques in bank loan prediction by machine learning are being applied with increased results in accuracy and performance. The Deep Learning Neural Network (DNN) method is one of the machine learning methods that currently has an important role in the big data era where big data, with capable machine capabilities and complexity in a feature can be handled by DNN. This research varies several architectures and parameters in the construction of the DNN model with the best score. Testing the bank loan status dataset using the DNN method yields an accuracy of $82.27 \%$ no better than the SVM method with an accuracy of $84 \%$. However, the DNN method is still better than other methods. Because the use of architectural variations and DNN parameters does not have a significant effect in producing the best score. The processed data really needs further processing before modeling is carried out.

Keywords: bank loan prediction, deep learning, dnn

\section{PENDAHULUAN}

Usaha simpan pinjam merupakan salah satu kegiatan utama yang dilakukan oleh lembaga keuangan maupun bank. Pendapatan utama dari usaha simpan pinjam tersebut berasal dari pendapatan bunga atas hasil penyaluran dana pinjaman kepada masyarakat maupun entitas yang membutuhkan. Namun usaha simpan pinjam tersebut dihadapkan pada risiko pihak nasabah yang tidak melaksanakan kewajiban melunasi pinjaman.

Salah satu dari 5 risiko yang menjadi tantangan terbesar dalam industri perbankan dan Lembaga Keuangan (berdasar hasil survey PWC 2018) yaitu risiko kredit(PricewaterhouseCoopers, 2018). Dampak dari kegagalan dalam mengatasi risiko kredit yaitu meningkatnya biaya yang akan mempegaruhi keuntungan bisnis. Dimana tingkat 
ketidaklancaran kredit dapat mengakibatkan terganggunya permasalahan keuangan dan berpotensi berhentinya kegiatan operasi perusahaan. NPL (nonperforming loan) atau rasio kredit bermasalah merupakan indikasi utama dalam mengukur kinerja lembaga keuangan serta alat untuk memitigasi kesehatan bisnis. Semakin tinggi NPL pada suatu bisnis simpan pinjam maka semakin tinggi nasabah yang memiliki risiko kredit yang tinggi.

Penilaian risiko kredit masih banyak dilakukan secara tradisional, manual, subjektif sehingga rawan terjadi fraud. Padahal, proses penentuan nasabah yang berpotensi bermasalah daripada yang baik adalah suatu hal yang penting karena dapat mempengaruhi usaha perbankan (Patel et al., 2020). Berbagai teknik dalam klasifikasi kreditur apakah digolongkan sebagai kreditur yang bakal melunasi atau akan menunggak pembayaran pinjaman telah banyak dilakukan baik secara akademik maupun dalam industry( $\mathrm{Lu}$ et al., 2020)(Kanapickiene \& Spicas, 2019)(Golbayani et al., 2020). Model klasifikasi dan regresi telah lama dipakai untuk mengklasifikasikan kualitas pinjaman dalam golongan baik maupun buruk. Bagaimanapun diantara 5 klasifier popular seperti Naïve Bayes, Logistic Regression, Random Forest, Decission Tree, dan k-NN, menunjukkan bahwa setiap klasifier memiliki kelebihan dan kelemahan masingmasing(Lu et al., 2020). Pada penelitian Kanapickiene, model logistic regression dikembangkan dengan menggunakan variable finansial dan non-finansial, namun dihasilkan bahwa variable non-finansial secara substansi tidak dapat memberi perkembangan yang berarti pada model yang dibangun(Kanapickiene \& Spicas, 2019).

Artificial Neural Network (ANN) merupakan sebuah system pemrosesan informasi yang didasarkan pada sistem kerja otak manusia yang pada prinsipnya seperti kumpulan sistem syaraf biologi yang memiliki kemampuan dapat mengekstrak data yang kompleks kedalam sebuah informasi tren dan pola tertentu(Kumar Gupta \& Goyal, 2018). ANN akan mempelajari bukan hanya informasi dalam data training namun termasuk noise pada data (Fan \& Yang, 2018). ANN dapat mengatasi masalah pada data besar dan terbukti dalam menangani masalah non-linear pada data.

Penelitian mengenai DNN telah dilakukan sebelumnya menghasilkan peningkatan akurasi pada DNN seiring dengan peningkatan ukuran dan kompleksitas suatu dataset(Economics \& Xxvi, 2019). Model DNN bersama linear regression model mampu memprediksi kelayakan pemohon pinjaman secara akurat dan minim kesalahan serta efisien dalam penggunaannya(Kumar Gupta \& Goyal, 2018). Pemodelan pada kelas pinjaman yang condong pada pinjaman yang aman, SMOTE digunakan untuk meningkatkan akurasi prediksi dengan DNN(Duan, 2019). Untuk mencapai dataset berimbang, model DNN digunakan clustering dan merging dengan $\mathrm{k}$-means dapat mempengaruhi hasil akurasi model(Li et al., 2018).
Pada penelitian ini permasalahan klasifikasi penentuan apakah kreditur mendapat predikat dapat melunasi hutangnya ataupun akan menunggak di kemudian hari, kami akan menggunakan Algoritma Deep Learning Neural Network untuk menangani permasalahan klasifikasi tersebut. Pada data yang sama, dilakukan data training dan data testing dengan menggunakan metode machine learning konvensional lainnya seperti k-NN, Decission Tree, Logistic Regression, Naïve Bayes, dan SVM.

Tujuan dari penelitian ini adalah untuk mengembangkan sistem prediksi status pinjaman melalui pelatihan dan pengujian data dengan menggunakan metode Deep Learning Neural Network dengan arsitektur yang paling sesuai sehingga dapat meminimalkan beban pekerjaan manusia dan meningkatkan akurasi dan reliabilitas dalam penilaian dan analisis risiko kredit. Kebaharuan dari penelitian ini adalah menggunakan beberapa variasi DNN untuk menemukan hasil terbaik kemudian dianalisa.

Pembahasan selanjutnya akan dijabarkan dalam bagian method, dataset dan evaluasi, hasil dan kesimpulan.

\section{METODOLOGI PENELITIAN}

Pembelajaran mesin merupakan suatu metode analisis data dan merupakan bagian dari kecerdasan buatan yang berdasarkan pada kemampuan mempelajari data yang ada sebelumnya, mengenali pola dan sebaran dari suatu data serta digunakan untuk membuat keputusan. Sistem ini membangun suatu model analitik yang terotomasi dengan meminimalkan campur tangan manusia.

\section{A. Deep Learning Neural Network (DNN)}

Jaringan syaraf tiruan merupakan struktur jaringan yang terdiri dari beberapa unit syaraf yang saling terhubung. Terdiri dari 3 lapisan yaitu lapisan masukan, lapisan tersembunyi dan lapisan keluaran. Bentuk jaringan syaraf tersebut menentukan respon/keluaran sesuai dengan unit syaraf yang terhubung. Struktur tersebut dapat disebut dengan perceptron. Jika jumlah lapisan tersembunyi lebih dari atau sama dengan dua, maka disebut dengan Multi Layer Perceptron (MLP) atau Deep Learning Neural Network (DNN)(Addo et al., 2018)(Fine, 2001).

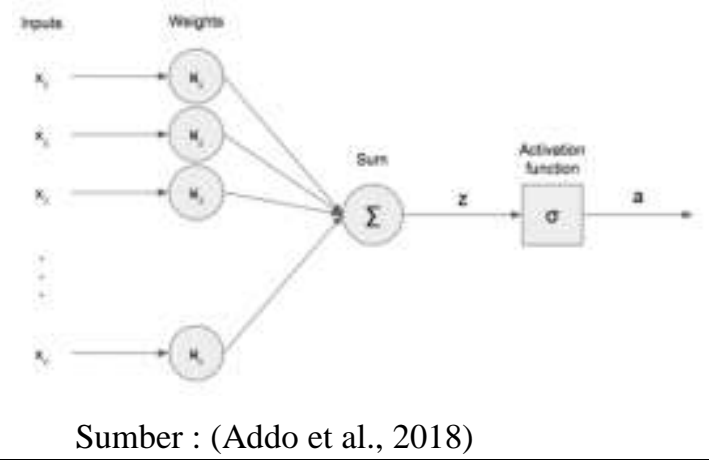

Sumber : (Addo et al., 2018) 


\section{Gambar. 1 Single Perceptron}

Pada gambar 1, menggambarkan bahwa setiap neuron atau single perceptron menerima masukan dari input layer $\left(\mathrm{x}_{\mathrm{i}-\mathrm{n}}\right)$. Setiap fitur $\mathrm{x}$ memiliki bobot (w) masing masing. Lalu pada setiap neuron, melakukan operasi linear dengan penjumlahan dari hasil pembobotan seluruh input $\Sigma\left(\mathrm{w}_{\mathrm{n}} \mathrm{x}_{\mathrm{n}}\right)$ dan ditambahkan bias (b). Hasilnya (z) akan dioperasikan dengan fungsi aktifasi $(\sigma)$. Maka secara formal dapat didefinisikan dengan persamaan (1) :

$$
y_{i}=\sigma\left\{\sum_{i=0}^{n} w^{i} x^{i}+b\right\}
$$

Fungsi aktivasi memngoperasikan hasil pembobotan input dan bias untuk menentukan apakah neuron diaktifkan atau tidak. Dengan memanipulasi data melalui proses gradient descent yang menghasilkan output untuk neural network(Nwankpa et al., 2018).

Sigmoid activation function dikaitkan dengan fungsi logistic atau non linear yang biasa dipakai dalam FFNN. Fungsi sigmoid pada persamaan (2) menghasilkan nilai mendekati 0 dan 1 . Sigmoid diterapkan pada output layer.

$$
\sigma=\frac{1}{\left(1+e x p^{-z}\right)}
$$

Fungsi aktivasi Rectified Linear Unit (ReLU) menghasilkan opearsi batas pada setiap element input dimana bernilai kurang dari nol akan sebagai nol, lebih dari nol sebagai fungsi linear. Fungsi ReLU dengan persamaan (3) diterapkan pada layer tersembunyi dalam DNN(Agarap, 2018).

$$
\sigma=\max (0, z)=\left\{\begin{aligned}
z_{i}, & \text { if } z_{i} \geq 0 \\
z, & \text { if } z_{i}<0
\end{aligned}\right.
$$

\section{B. Arsitektur}

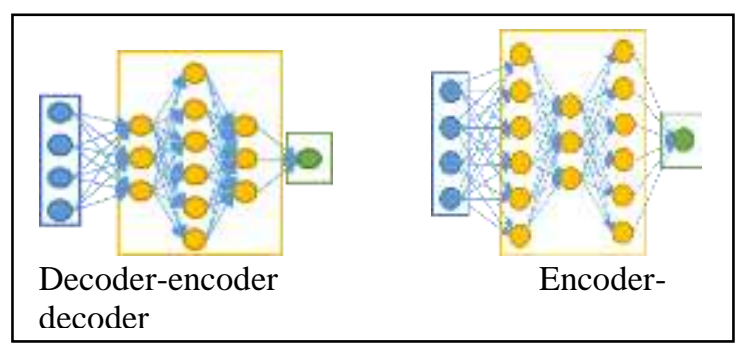

Sumber : (Addo et al., 2018)

\section{Gambar 2. Arsitektur Deep Learning Neural Network}

Terdapat beberapa jenis arsitektur neural network, diantaranya adalah feedforward network, recurrent network, dan radial basis function network. Model feedforward neural network (FFNN) merupakan salah satu model yang sering digunakan untuk tujuan prediksi(Fine, 2001)(Suhermi et al., 2019).
Penelitian ini menggunakan arsitektur FFNN dimana keseluruhan titik neuron terhubung penuh kesemua titik neuron pada layer yang bertetanggaan.

Menjelaskan kronologis penelitian, termasuk desain penelitian, prosedur penelitian (dalam bentuk algoritma, Pseudocode atau lainnya), bagaimana untuk menguji dan akuisisi data. Deskripsi dari program penelitian harus didukung referensi, sehingga penjelasan tersebut dapat diterima secara ilmiah.

Paramater DNN yang digunakan pada penelitian ini adalah arsitektur encoder maupun encoderdecoder, variasi jumlah hidden layer 2,3 dan 4, oprimizer SGD, RMPS Rop dan Adam, variasi epoch 50,30,dan 100, variasi learning rate 0.001, $0.01,0.1,00.2,0.02$ dan 0.2 .

Penelitian ini menggunakan model penelitian ini dapat dimodifikasi dengan variasi parameter diantaranya adalah memvariasikan jumlah hidden layer, jumlah neuron pada setiap layer, batch size, epochs, learning rate, optimizer.maupun variabel yang dianalisa dapat mempengaruhi hasil penelitian.

\section{HASIL DAN PEMBAHASAN}

\section{(2) Data Description}

Dalam dunia nyata, seringkali ditemukan data yang kotor dan tidak lengkap. Langkah awal yang dilakukan dalam masalah prediksi terkait penilaian status pinjaman adalah membersikan data yang akan diolah hingga diperoleh informasi yang paling berguna sebisa mungkin. Pada penelitian ini, kami menggunakan dataset Bank Loan Status Dataset yang diperoleh dari Kaggle. Dataset terdiri dari 19 fijtur dan 100514 instance, yang informasinya terdapat pada Tabel 1.

Tabel 1. Dataset

\begin{tabular}{ll}
\hline Kolom & Keteragan \\
\hline 'loanID' & ID pinjaman \\
'customerID' & ID Peminjam/Nasabah \\
'loan_status' & Status Pinjaman \\
'cur_loan_amt' & Current Loan Amount (NIlai \\
Pinjaman) \\
'term' & Jangka waktu pinjaman \\
'cr_score' & Score kredit \\
'ann_income' & Penghasilan tahunan \\
'years_in_current_job' & Lama bekerja \\
'home_ownership' & Status kepemilikan rumah \\
'purpose' & tujuan / keperluan pinjaman \\
'monthly_debt' & angsuran bulanan \\
'years_cr_history', & lama (tahun) riwayat \\
pinjaman tersedia \\
'last_delinquent' & lama bulan terakhir setelah \\
\hline
\end{tabular}




\begin{tabular}{|c|c|}
\hline Kolom & Keteragan \\
\hline & $\begin{array}{l}\text { dinyatakan sebagai } \\
\text { peminjam nakal }\end{array}$ \\
\hline 'open_acc' & $\begin{array}{l}\text { jumlah akun rekening } \\
\text { pinjaman }\end{array}$ \\
\hline 'cr_problems' & $\begin{array}{l}\text { jumlah rekening kredit yang } \\
\text { bermasalah }\end{array}$ \\
\hline 'cr_balance' & $\begin{array}{l}\text { saldo pinjaman (sisa } \\
\text { pinjaman) }\end{array}$ \\
\hline 'max_open_cr' & $\begin{array}{l}\text { plafon kredit / maksimal } \\
\text { nilai pengajuan kredit }\end{array}$ \\
\hline 'bankruptcies' & mengalami kebangkrutan \\
\hline 'tax_liens' & $\begin{array}{l}\text { memiliki masalah/tunggakan } \\
\text { pajak }\end{array}$ \\
\hline
\end{tabular}

Terdapat dua kelas data sebagaimana pada Gambar 2 yang akan menjadi kelas target pada kolom "Loan Status" dengan nilai "Fully Paid" dan "Charged Off".

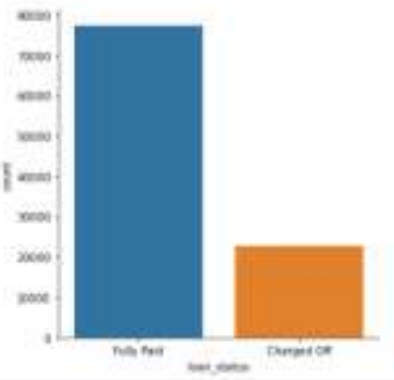

Sumber : (Syafrudin et al., 2021)

Gambar 3. Target Class Distribution.

Pada tahap pre-prcessing, kolom LoanID dan customerID tidak akan dipakai dalam data training karena tidak berguna dalam model prediksi, oleh karena itu dihapus dari data training. Loan status merupakan kelas target yang akan dikonversi dengan data dummy 0 dan 1 .

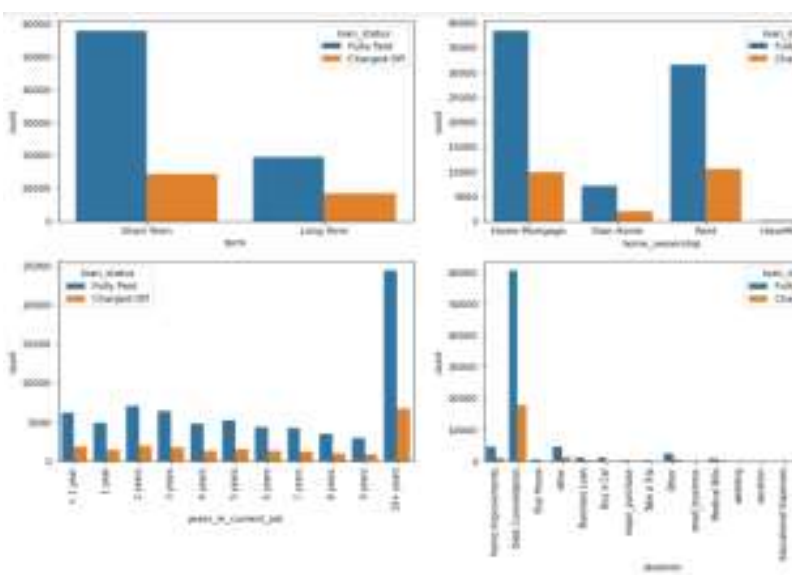

Sumber: (Syafrudin et al., 2021)

Gambar 4. Distribusi data kategori data numerik(Duan, 2019). Kolom 'term', 'home ownership' dan 'purpose' akan dikonversi dengan one hot encoding dimana nilai pada kolom tersebut dipecah sebanyak nilai uniknya(Duan, 2019). Kolom years in current job akan dikonversi sesuai nilai tahun lama bekerja.

Data yang tidak lengkap atau bernilai null ditemukan pada dataset, dalam hal terjadi data yang kosong melebihi $50 \%$ dari jumlah instance, maka fitur 'last_delinquent' dilakukan penghapusan atas fitur tersebut. Lalu dilanjutkan dengan menghapus baris data yang memiliki ketidaklengkapan nilai fitur. Dari pemrosesan dan pembersihan data dihasilkan 77271 instance dengan 34 kolom.

Proses normalisasi dilakukan untuk mentransformasikan nilai data besar kepada nilai yang lebih sederhana(Arutjothi, 2017). Normalisasi Min-Max diterapkan pada fitur: 'cur_loan_amt', 'cr_score', 'ann_income', 'open_acc', 'years_in_current_job', 'monthly_debt', 'years_cr_history', 'cr_problems', 'tax_liens', 'cr_balance', 'max_open_cr', 'bankruptcies'.

\section{Kriteria Evaluasi}

Terdapat beberapa cara dalam pengukuran kinerja suatu model untuk membandingkan kinerja suatu model yakni AUC, RMSE, MSE, ROC, dengan beberapa tambahan pengukuran seperti F-score, recall dan precision. Paper ini akan menggunakan penilaian model dengan RMSE.

Terdapat beberapa parameter dalam suatu arsitektur DNN, yang pada penelitian ini, dilakukan eksperimen beberapa variasi parameter diantaranya adalah memvariasikan jumlah hidden layer, jumlah neuron pada setiap layer, batch size, epochs, learning rate, dan optimizer. Fungsi aktivasi Relu diterapkan pada hidden layer, sedangkan sigmoid diterapkan pada layer keluaran. Lalu penggunaan GridSearch dilakukan untuk menemukan parameter terbaik dari model yang dibangun pada data latih. Sehingga model dengan parameter terbaik yang akan digunakan dalam melakukan pengujian data testing. Loss function 'binary_crossentropy' diterapkan dalam training dataset.

Teknik train-test split dijalankan dalam mengevaluasi kinerja algoritma dimana dataset dibagi secara acak kedalam dua subset data. Pertama, dataset yang digunakan sebagai fit model atau data training sebesar 80\%nya. Kedua, dataset yang digunakan sebagai data tes sebesar $20 \%$ sisanya.

Hasil eksperimen dinyatakan dalam Tabel II, menunjukkan bahwa dengan memvariasikan beberapa model arsitektur dan parameter dalam DNN, dihasilkan best score terbaik pada model ke 4 dengan nilai akurasi $82.32 \%$.

Sebelum dipakai sebagai input dalam model DNN, data kategorikal seperti pada Gambar 3, diperlukan penanganan berupa konversi menjadi 
Tabel II. Variasi Model Arsitektur dan Parameter

\begin{tabular}{|c|c|c|c|c|c|}
\hline Model & $\begin{array}{c}\text { Arsitekt } \\
\text { ur }\end{array}$ & $\begin{array}{c}\text { rsitektur } \\
\text { Hidden } \\
\text { Layer } \\
\text { dan } \\
\text { Node }\end{array}$ & $\begin{array}{c}\text { Optimi } \\
\text { zer }\end{array}$ & Best Param & $\begin{array}{c}\text { Best } \\
\text { Score }\end{array}$ \\
\hline 1 & Encoder & $\begin{array}{l}2 \text { 20] } \\
\text { 20] }\end{array}$ & Adam & $\begin{array}{l}\text { 'batch_size': } 200, \\
\text { 'epochs': } 50, \\
\text { 'learn_rate': } 0.01\end{array}$ & $\begin{array}{l}0.8231 \\
65\end{array}$ \\
\hline 2 & Encoder & $\begin{array}{l}3 \quad[90, \\
30,10]\end{array}$ & Adam & $\begin{array}{l}\text { 'batch_size': 200, } \\
\text { 'epochs': } 50, \\
\text { 'learn_rate': } 0.1\end{array}$ & $\begin{array}{l}0.8228 \\
99\end{array}$ \\
\hline 3 & Encoder & $\begin{array}{l}4 \quad[300, \\
200, \\
100,20]\end{array}$ & Adam & $\begin{array}{l}\text { 'batch_size': } 300, \\
\text { 'epochs': } 30, \\
\text { 'learn_rate': } 0.2\end{array}$ & $\begin{array}{l}0.8229 \\
75\end{array}$ \\
\hline 4 & $\begin{array}{l}\text { Encode } \\
\mathbf{r}- \\
\text { Decoder }\end{array}$ & $\begin{array}{l}3[100, \\
30,100]\end{array}$ & SGD & $\begin{array}{ll}\text { batch_size': } & 100, \\
\text { 'epochs': } & 150, \\
\text { 'learn_rate': } & 0.02\end{array}$ & $\begin{array}{l}0.8232 \\
41\end{array}$ \\
\hline 5 & $\begin{array}{l}\text { Encoder } \\
- \\
\text { Decoder }\end{array}$ & $\begin{array}{l}3 \quad[100 \\
30,100]\end{array}$ & $\begin{array}{l}\text { RMSP } \\
\text { rop }\end{array}$ & $\begin{array}{l}\text { 'batch_size': } 50, \\
\text { 'epochs': } 50, \\
\text { 'learn_rate': } 0.1\end{array}$ & $\begin{array}{l}0.8231 \\
27\end{array}$ \\
\hline 6 & $\begin{array}{l}\text { Encoder } \\
- \\
\text { Decoder }\end{array}$ & $\begin{array}{l}3 \quad[100 \\
30,100]\end{array}$ & Adam & $\begin{array}{l}\text { 'batch_size': } 100, \\
\text { 'epochs': } 30, \\
\text { 'learn_rate': } 0.2\end{array}$ & $\begin{array}{l}0.8230 \\
13\end{array}$ \\
\hline 7 & $\begin{array}{l}\text { Encoder } \\
- \\
\text { Decoder }\end{array}$ & $\begin{array}{l}4 \quad[100, \\
30, \quad 30, \\
100]\end{array}$ & SGD & $\begin{array}{ll}\text { 'batch_size': } & 50, \\
\text { 'epochs': } & 50, \\
\text { 'learn_rate': } 0.02\end{array}$ & $\begin{array}{l}0.8232 \\
41\end{array}$ \\
\hline 8 & $\begin{array}{l}\text { Decoder } \\
- \\
\text { Encoder }\end{array}$ & $\begin{array}{l}3 \quad[30, \\
100,30]\end{array}$ & SGD & $\begin{array}{ll}\text { 'batch_size': } & 200, \\
\text { 'epochs': } & 100, \\
\text { 'learn_rate': } & 0.1\end{array}$ & $\begin{array}{l}0.8232 \\
03\end{array}$ \\
\hline 9 & $\begin{array}{l}\text { Decoder } \\
- \\
\text { Encoder }\end{array}$ & $\begin{array}{l}3 \quad[30, \\
100,30]\end{array}$ & Adam & $\begin{array}{l}\text { 'batch_size': } 300 \text {, } \\
\text { 'epochs': } 30 \text {, } \\
\text { 'learn_rate': } 0.2\end{array}$ & $\begin{array}{l}0.8232 \\
41\end{array}$ \\
\hline 10 & $\begin{array}{l}\text { Decoder } \\
- \\
\text { Encoder }\end{array}$ & $\begin{array}{l}3 \quad[30, \\
100,30]\end{array}$ & $\begin{array}{l}\text { RMSP } \\
\text { rop }\end{array}$ & $\begin{array}{lr}\text { 'batch_size': } & 100, \\
\text { 'epochs': } & 30, \\
\text { 'learn_rate': } & 0.02\end{array}$ & $\begin{array}{l}0.8231 \\
65\end{array}$ \\
\hline 11 & $\begin{array}{l}\text { Decoder } \\
- \\
\text { Encoder }\end{array}$ & $\begin{array}{l}4 \quad[30, \\
100, \\
100,30]\end{array}$ & SGD & 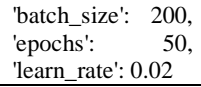 & $\begin{array}{l}0.8232 \\
03\end{array}$ \\
\hline
\end{tabular}

Sumber : (Syafrudin et al., 2021)

* Eksperimen dijalankan dengan variasi: batch_size = $[100,200,250,300]$, epochs $=[30,50,100]$, learn_rate $=$ $[0.001,0.01,0.02,0.1,0.2]$

Pengukuran seberapa baik model DNN ini jika dibandingkan dengan model konvensional lainnya dilakukan juga dalam penelitian. Dengan dataset yang sama telah dilakukan pengujian melalui melakukan testing data dengan parameter terbaik yang telah dihasilkan dalam eksperimen sebelumnya.

Hasil pengujian metode DNN dan perbandingannya dengan model konvensional dihasilkan sesuai pada tabel III. Hasil menunjukkan bahwa prediksi status pinjaman dengan metode DNN menghasilkan akurasi $82.27 \%$ tidak lebih baik dari metode SVM dengan hasil akurasi 84\%. Namun metode DNN masih lebih baik dibandingkan dengan metode lainnya.

Tabel III. Hasil Akurasi Pengujian Model Prediksi

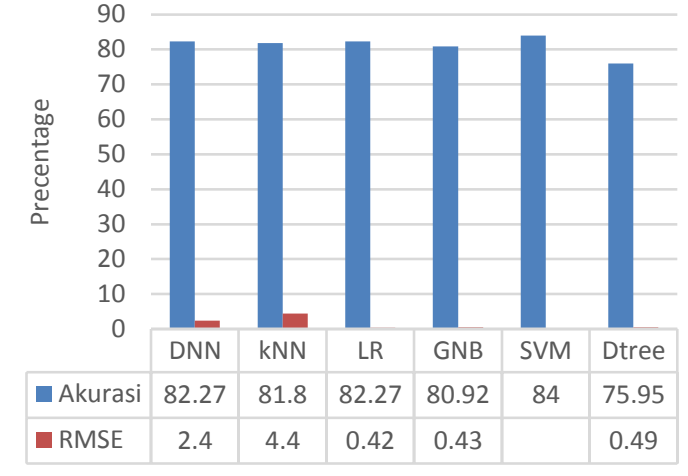

Sumber : (Syafrudin et al., 2021)

\section{KESIMPULAN}

Suatu MLP atau DNN yang terdiri dari 3 hingga 5 layer dilatih dalam eksperimen pada prediksi status pinjaman dengan memvariasikan beberapa model arsitektur dan parameter. Sebanyak 11 variasi model arsitektur DNN dengan masing-masing menerapkan variasi parameter pada jumlah neuron, optimizer, batch size epoch dan learning rate dihasilkan score terbaik pada $82.32 \%$ akurasi. Bila dibandingkan dengan metode konvensional klasifikasi lainnya, model DNN tidak menghasilkan akurasi yang lebih baik dibanding dengan menggunakan metode SVM, namun masih lebih baik dibandingkan dengan metode linear regression, kNN, gaussian $\mathrm{NB}$ dan decision tree. Hasil yang kurang baik tersebut menunjukkan penggunaan variasi arsitektur dan parameter DNN yang tidak berpengaruh signifikan dalam menghasilkan score terbaik. Sehingga untuk penelitian selanjutnya dapat dilakukan percobaan variasi parameter lebih beragam dan menganalisa variabel terbaik prediksi pinjaman bank.

\section{REFERENSI}

Addo, P. M., Guegan, D., \& Hassani, B. (2018). Credit risk analysis using machine and deep learning models. Risks, 6(2), 1-20. https://doi.org/10.3390/risks6020038

Agarap, A. F. M. (2018). Deep Learning using Rectified Linear Units (ReLU). ArXiv, 1, 2-8.

Arutjothi, G. (2017). Prediction of Loan Status in Commercial Bank using Machine Learning Classifier. 2017 International Conference on Intelligent Sustainable Systems (ICISS), Iciss, 416-419.

Duan, J. (2019). Financial system modeling using deep neural networks (DNNs) for effective risk assessment and prediction. Journal of the Franklin Institute, 356(8), 4716-4731. https://doi.org/10.1016/j.jfranklin.2019.01.046

Economics, A., \& Xxvi, V. (2019). A Deep Neural 
Network (DNN) based classification model in application to loan default prediction. Theoretical and Applied Economics, XXVI(4), 75-84.

Fan, Q., \& Yang, J. (2018). A denoising autoencoder approach for credit risk analysis. $A C M$ International Conference Proceeding Series, 62-65.

https://doi.org/10.1145/3194452.3194456

Fine, T. L. (2001). Feedforward Neural Network Methodology. IEEE Transactions on Neural Networks, 12(3), 647-648. https://doi.org/10.1109/TNN.2001.925573

Golbayani, P., Wang, D., \& Florescu, I. (2020). Application of Deep Neural Networks to assess corporate Credit Rating. ArXiv, 1-18.

Kanapickiene, R., \& Spicas, R. (2019). Credit risk assessment model for small and microenterprises: The case of Lithuania. Risks, 7(2), 1-23. https://doi.org/10.3390/risks7020067

Kumar Gupta, D., \& Goyal, S. (2018). Credit Risk Prediction Using Artificial Neural Network Algorithm. International Journal of Modern Education and Computer Science, 10(5), 9-16. https://doi.org/10.5815/ijmecs.2018.05.02

Li, Y., Lin, X., Wang, X., Shen, F., \& Gong, Z. (2018). Credit Risk Assessment Algorithm Using Deep Neural Networks with Clustering and Merging. Proceedings - 13th International Conference on Computational Intelligence and Security, CIS 2017, 2018-Janua, 173-176. https://doi.org/10.1109/CIS.2017.00045

Lu, Y., Wang, Y., Zhang, Y., Lu, Y., Yu, X., \&
Wang, Y. (2020). A Comparative Assessment of Credit Risk Model Based on Machine Learning. Procedia Computer Science, 174, 141-149. https://doi.org/10.1016/j.procs.2020.06.069

Nwankpa, C. E., Ijomah, W., Gachagan, A., \& Marshall, S. (2018). Activation functions: Comparison of trends in practice and research for deep learning. ArXiv, 1-20.

Patel, B., Patil, H., Hembram, J., \& Jaswal, S. (2020). Loan default forecasting using data mining. 2020 International Conference for Emerging Technology, INCET 2020, 7-10. https://doi.org/10.1109/INCET49848.2020.91 54100

PricewaterhouseCoopers. (2018). 2018 Indonesia Banking Survey Technology shift in Indonesia is underway. February, 48.

Suhermi, N., Suhartono, S., Dana, I. M. G. M., \& Prastyo, D. D. (2019). Pemilihan Arsitektur Terbaik pada Model Deep Learning Melalui Pendekatan Desain Eksperimen untuk Peramalan Deret Waktu Nonlinier. STATISTIKA: Journal of Theoretical Statistics and Its Applications, 18(2), 153-159. https://doi.org/10.29313/jstat.v18i2.4545

Syafrudin, S., Nugraha, A. R., \& Handayani, K. (2021). Prediksi Status Pinjaman Bank dengan Deep Learning Neural Network (DNN). 